\title{
Evaluation of stressors in intensive care units
}

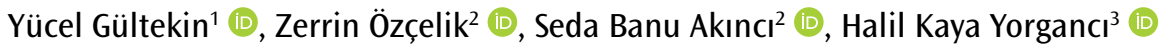

\section{ABSTRACT}

ORCID IDs of the authors:

Y.G. 0000-0002-1974-1242

Z.0.0.0000-0001-5761-2022

S.B.A. 0000-0002-8538-6955

H.K.Y $0000-0003-4376-289 X$

\section{Cite this paper as: \\ Gültekin Y, ÖzçelikZ, \\ Akınc SB, Yorgancı HK. A \\ Evaluation of stressors in \\ intensive care units. Turk \\ Surg 2018; 34: 5-8.}

'Division Intensive Care, Department of General Surgery, Hacettepe University School of Medicine, Ankara, Turkey

2Division Intensive Care, Department of Anesthesiology and Reanimation, Hacettepe University School of Medicine, Ankara, Turkey

${ }^{3}$ Department of General Surgery, Hacettepe University School of

Medicine, Ankara, Turkey

This study was presented at the $13^{\text {th }}$ Congress of the Turkish Society of Medical and Surgical Intensive Care Medicine, 2-5 November 2016, Izmir, Turkey.

Address for Correspondence Yücel Gültekin

e-mail: drycl68@hotmail.com

Received:06.11.2016

Accepted: 31.01 .2017

Available Online Date: 04.01.2018

CCopyright 2018

by Turkish Surgical Association

Available online at

www.turkjsurg.com
Objective: Physical and psychological stressors adversely affect the treatment and length of stay of patients in intensive care units. In this study, we aimed to describe environmental and psychological stressors affecting intensive care unit patients and to determine their priorities.

Material and Methods: In this study, the 40-item Intensive Care Unit Environmental Stressor Scale was administered to patients in the General Surgery Intensive Care Unit and the Anesthesiology and Reanimation Intensive Care Unit. The patients' age, gender, marital status, educational status, cause of hospitalization, and intensive care unit length of stay were questioned and recorded. Acute Physiology And Chronic Health Evaluation II scores were determined for intensive care unit patients.

Results: A total of 98 patients, 80 in the General Surgery Intensive Care Unit and 18 in the Anesthesiology and Reanimation Intensive Care Unit, were included in the study between May 1, 2015 and October 31, 2015. Fifty-six of the patients were male (57.1\%) and 42 were female (42.9\%). The mean age of the patients was $55.1 \pm 15.1$ years. The mean intensive care unit length of stay was $3.4 \pm 1.6$ days. The median Acute Physiology And Chronic Health Evaluation II score of the patients was 6 ( 0 to 17 ). The patients were most affected by thirst (mean 2.44). The second most stressful stress factor was the presence of tubes in the mouth and nose (mean 2.25). The least stressful factor for the patients was the presence of nurses constantly performing activities around the bed. Although $51 \%$ of the patients were postoperative, pain was ranked 5th among stress factors.

Conclusion: The environmental and psychological factors affecting intensive care unit patients varied according to age, sex, and educational and surgical status. These factors had adverse effects on the patients. The elimination or modification of these factors would contribute positively to the treatment of intensive care unit patients and shorten their length of stay in the intensive care unit.

Keywords: Environmental, intensive care, psychological, stress

\section{INTRODUCTION}

The intensive care unit (ICU) is a new and different environment for patients. Patients are exposed to unusual sounds and smells in the ICU. An unfamiliar medical team provides care for these patients (1, 2). The treatment process of the intensive care patient is extended to these external factors by adding psychological factors such as not being able to fully understand the disease, having no information about the treatment process and being away from the family $(3,4)$. Factors such as pain, unfamiliar and unusual noises, and constant ambient light disturb the sleeping patterns of critically ill ICU patients. Sleep disturbances can elevate blood pressure, impair immune system function, and lead to a negative nitrogen balance. Delirium is a common disorder in ICUs. Although the impact of the environment on delirium is not clear, it has been stated that the ICU environment may be a contributing factor to the development of delirium (5-7). The addition of conditions such as sleep disturbance and delirium triggered by environmental factors to existing medical conditions has negative effects on the treatment process of disease. Environmental stressors vary according to factors such as age, sex, and educational and surgical status (4). Therefore, describing the physical and psychological factors affecting ICU patients and determining their degrees of influence are important for effective follow-up and treatment.

In this study, we aimed to describe environmental and psychological factors affecting ICU patients using the Intensive Care Unit Environmental Stressor Scale (ICUESS) and to determine the priorities of these factors, especially in patients who did and did not undergo surgery.

\section{MATERIAL AND METHODS}

This study was approved by the Non-interventional Clinical Research Ethics Board of Hacettepe University Faculty of Medicine. The ICUESS was administered to patients in the General Surgery Intensive Care Unit (GSICU) and the Anesthesiology and Reanimation Intensive Care Unit (ARICU) in Hacettepe University School of Medicine. The patients' age, gender, marital status, educational status, cause of hospitalization, and ICU length of stay were questioned and recorded. APACHE II scores were determined for the ICU patients. 


\section{Patient Group}

Patients who were hospitalized from 24 hours to 7 days between May 1, 2015 and October 31, 2015 in the GSICU with nine beds and the ARICU with four beds in Hacettepe University Faculty of Medicine were enrolled in the study. Patients who were under 18 years of age, had persistent neurological damage, had psychological problems, whose general condition prevented them from answering questions, and who had previously stayed in the ICU were excluded from the study. Written consent was obtained from the patients who participated in the study.

\section{The Intensive Care Unit Environmental Stressor Scale}

The validity and reliability of the scale administered in the study were determined by Ballard (8) and Nastasy (9). Permission was obtained to use the scale at the beginning of the study. The ICUESS was translated into Turkish and culturally adapted before its application. The scale was translated from English to Turkish by two independent persons. 10 persons from different socio-cultural levels compared the two translations. A group of hospital staff, patient and patients relatives made choices in terms of independence of the individual, more easily understood from the word differences between the translators A Turkish version of the scale was created by the two independent translators; also, the Turkish version of the scale was re-translated into English by a different person. An independent person with good English skills compared the translation to the original scale and supervised the translation. The Turkish version of the scale was administered to ICU patients, and its clarity was confirmed. The patients were informed about the scale before it was applied. The patients were asked 40 questions. Each question in the scale was assessed as (1) not stressful; (2) moderately stressful; (3) very stressful; or (4) extremely stressful.

\section{Statistical Analysis}

The data were evaluated using Statistical Package for the Social Sciences version 15.0 software (SPSS Inc.; Chicago, IL, USA). The variables were investigated using visual (histogram and probability plots) and analytical (Kolmogorov-Smirnov/ Shapiro-Wilk tests) methods to determine whether they were normally distributed. The descriptive analyses were presented using mean and standard deviation for normally distributed variables. Cross-tabulations were performed for age, gender, marital status, educational and surgical status, and ICU length of stay with the stress factors on the scale. The difference between the groups was compared using the chi-square test or Fisher's exact test. $\mathrm{p}$-values less than 0.05 were considered statistically significant.

\section{RESULTS}

A total of 98 patients, 80 in the GSICU and 18 in the ARICU, were included in the study between May 1, 2015 and October 31, 2015. Fifty-six patients were male (57.1\%) and 42 were female (42.9\%). The mean age of the patients was $55.1 \pm 15.1$ years. The mean ICU length of stay was $3.4 \pm 1.6$ days. The median APACHE II score of the patients was 6 (0 to 17). Fifty-one per cent of the patients were postoperative (50 patients); $49 \%$ of the patients were medical (48 patients). The rates of illiteracy, literacy, and elementary, middle school, high school, and university education were $10.2 \%, 4.1 \%, 28.6 \%, 8.2 \%, 14.3 \%$, and $34.7 \%$, respectively.
Table 1. Ranking of stressors

\begin{tabular}{|l|c|}
\hline 1- Thirst & Mean \\
\hline 2- Presence of tubes in the nose or mouth & 2.44 \\
\hline 3- Not being in control of yourself & 2.25 \\
\hline 4- Inability to sleep & 2.22 \\
\hline 5- Pain & 2.11 \\
\hline 6- Inability to move hands due to i.v. line & 2.05 \\
\hline 7- Seeing family and friends for only a few minutes each day & 1.91 \\
\hline 8- Being in a room that is too hot or too cold & 1.98 \\
\hline 9- Having lights on constantly & 1.70 \\
\hline 10- Having to look at the pattern of holes in the ceiling & 1.66 \\
\hline 11- Unfamiliar and unusual noises & 1.64 \\
\hline 12- Being aware of unusual smells around you & 1.63 \\
\hline 13- Hearing buzzers and alarms from machinery & 1.62 \\
\hline 14- Hearing other patients cry out & 1.59 \\
\hline 15- Missing husband or wife & 1.58 \\
\hline
\end{tabular}

16- Not knowing when to expect things will be done to you 1.56

17- Being stuck with needles 1.54

18- Not having treatments explained to you 1.53

19- Uncomfortable bed and/or pillow

20- Being bothered 1.46

21- Having to wear oxygen 1.46

22- Not knowing what time it is 1.46

23- Not knowing what day it is 1.39

24- Having blood pressure taken often each day 1.38

25- Having the team use words you cannot understand

26- Nurses and doctors talking too loudly 1.34

27- Being cared for by unfamiliar doctors 1.34

28- Hearing the heart monitor alarm go off 1.27

29- Being awakened by nurses 1.26

30- Having strange machines around you

31- Not having the nurses introduce themselves 1.21

32- Constantly being examined by doctors and nurses 1.19

33- Feeling the nurses are watching the machines more closely than they are watching you

34- Lack of privacy

35- Having nurses be in too much of a hurry

1.14

36- Seeing i.v. bags hanging over your head 1.13

37- Not knowing where you are

1.13

38- Hearing the telephone ring

1.11

39- Being tied down by tubes 1.10

40- Presence of nurses constantly performing activities around your bed

1.10

1.09

The patients were most affected by thirst (mean 2.44). The second most stressful factor was the presence of tubes in the mouth and nose (mean 2.25). The least stressful factor was the presence of nurses constantly performing activities around the bed (Table 1). Postoperative patients were most affected 
Table 2. Ranking of stressors among postoperative patients and medical patients

\begin{tabular}{|lcll|}
\hline Postoperative patients & Mean & Medical patients & Mean \\
\hline 1- Thirst & 2.61 & 1- Thirst & 2.27 \\
\hline 2- Presence of tubes in the nose or mouth & 2.44 & 2- Not being in control of yourself & 2.27 \\
\hline 3- Not being in control of yourself & 2.17 & 3- Being in a room that is too hot or too cold & 2.18 \\
\hline 4- Inability to sleep & 2.10 & 4- Inability to sleep & 2.12 \\
\hline 5- Pain & 2.06 & 5- Inability to move your hands due to i.v. line & 2.10 \\
\hline
\end{tabular}

Table 3. Ranking of stressors among age $\leq 40$ and age $>40$ ICU patients

\begin{tabular}{|lcll|}
\hline Age $\leq \mathbf{4 0}$ ICU patients & Mean & Age $>\mathbf{4 0}$ ICU patients & Mean \\
\hline 1- Seeing family and friends for only a few minutes each day & 2.67 & 1- Thirst & 2.48 \\
\hline 2- Thirst & 2.28 & 2- Presence of tubes in the nose or mouth & 2.25 \\
\hline 3- Presence of tubes in the nose or mouth & 2.24 & 3- Not being in control of yourself & 2.23 \\
\hline 4- Not being in control of yourself & 2.18 & 4- Inability to sleep & 2.14 \\
\hline 5- Pain & 2.06 & 5- Pain & 2.05 \\
\hline
\end{tabular}

ICU: intensive care unit

by thirst (mean 2.61). Medical patients were most affected by thirst and not being in control of themselves (mean 2.27) (Table 2). Pain was the fifth greatest stressor in postoperative patients (mean 2.04). There was no statistically significant difference between patients who did and did not undergo surgery in terms of pain $(p=0.65)$ and inability to sleep $(p=0.94)$.

There was no statistically significant difference between college graduates and non-college graduates in terms of lack of privacy $(p=0.27)$. There was no statistically significant difference between male and female patients in terms of lack of privacy $(p=0.07)$. Patients over the age of 40 were most affected by thirst (mean 2.48). Patients under the age of 40 were most affected by seeing family and friends for only a few minutes each day (mean 2.67) (Table 3). Male patients were most affected by thirst, followed by the presence of tubes in the mouth and nose. Female patients were most affected by not being in control of themselves and the presence of tubes in the mouth and nose, respectively.

\section{DISCUSSION}

Patients are exposed to psychological factors such as separation from family, dependence on bed and health personnel, and environmental factors such as unfamiliar devices, sounds, and smells in the ICU. Studies on determining the priorities of these physical and psychological factors and eliminating them in ICU patients would contribute positively to the treatment process of ICU patients.

Cornock (10) stated that thirst was the most common stressor and the presence of tubes in the mouth and nose was the second most common stressor. In our study, thirst was the most common stressor. Cochran and Ganong (11) found that the presence of tubes in the mouth and nose was the most disturbing stress factor for patients. Similarly, Hweidi et al. (1) found that the presence of tubes in the mouth and nose was the most disturbing stress factor for patients. In our study, we found that the presence of tubes in the mouth and nose was the second most common stress factor, in accordance with the study by Cornock (10).
Failure to detect or treat pain can lead to complications involving the cardiovascular, pulmonary, and neurological systems. Good pain control decreases these complications (12). In Malaysia, Soh et al. (13) found that pain was the most frequent complaint of patients. In our study, although $51 \%$ of the patients were postoperative, pain was ranked 5th among stress factors. There was no statistically significant difference between postoperative and medical ICU patients in terms of pain. The low pain ranking suggested that sufficient pain control was provided because pain was frequently assessed with various scoring systems in our ICU.

We found that ICU patients were less affected by the presence of unfamiliar devices, smells and noise. This situation suggested that awareness of critical illness and intensive care have increased. In our study, approximately $50 \%$ of the patients were high school and college graduates. We believe that the high level of education contributed to the fact that the patients were less affected by these stressors. We found that most of the patients had already been followed up by doctors and nurses; therefore, they were less anxious about their situations and futures. The least stressful factor for the patients was the presence of nurses constantly performing activities around the bed. We believe that the patients had confidence in the doctors and nurses.

Intensive care unit patients are often bedridden; also, their basic needs are met by medical personnel. Lack of privacy can be a stressor for patients (14). In our study, lack of privacy was ranked 34th among the stress factors in the ICU. There was no statistically significant difference between male and female patients regarding lack of privacy. There was no statistically significant difference between college graduates and noncollege graduates regarding lack of privacy. This situation suggested that curtains/screens are frequently used in the ICUs, nurses and health personnel consider the discomfort patients may experience due to their physical condition when planning patient care, and a relaxing environment is provided for patients. Intensive care units are noisy environments due 
to the nature of the working environment and the technical equipment and alarms used. Noise and light in the ICU cause sleep disorders in patients (15). Inability to sleep in the ICU was ranked 4th among the stress factors in our study. In China, So and Chan (16) stated that inability to sleep was ranked 3rd among stress factors.

The ICU is a stressful environment with many environmental and psychological factors that affect patients. It should be known that some of these factors can be changed or reduced. Puntillo et al. (17) reported that some stress factors in the ICU are subjective and can be modified. They stated that thirst, which was ranked 1st among stress factors in the ICU, can be reduced with simple and inexpensive methods such as placing wet gauze on the lips and using cold water sprays. Environmental factors such as noise, light, and temperature, which lead to sleep disorders, are controllable stressors in the ICU. Moreover, when considering the working conditions of the ICU and the psychological needs of patients, the physical and psychological stressors of ICU patients can be removed or reduced with interchangeable factors such as frequent evaluation of the necessity for tubes in the nose and mouth and vascular accesses as well as their timely withdrawal, effective control of pain monitored by scoring systems, and well-organized visiting hours.

We believe the limitations of this study are low APACHE II scores, short ICU lengths of stay, and inclusion of patients from the GSICU and ARICU.

\section{CONCLUSION}

It is important to determine the environmental and psychological factors that affect patients in ICUs. These factors can vary according to age, sex, and educational and surgical status; also, their priorities may change. Elimination or modification of these factors would contribute positively to the treatment of ICU patients and their length of stay in the ICU.

Ethics Committee Approval: Ethics committee approval was received for this study from the ethics committee of Hacettepe University School of Medicine Non-interventional Clinical Research Ethics Board.

Informed Consent Written informed consent was obtained from patient who participated in this study.

Peer-review: Externally peer-reviewed.

Author Contributions: Concept - Y.G., Z.Ö., S.B.A., H.K.Y.; Tasarım Design - Y.G., Z.Ö., S.B.A.; Supervision - Y.G., Z.Ö., H.K.Y.; Resource - Y.G., Z.Ö.; Materials - Y.G., Z.Ö.; Data Collection and/or Processing - Y.G., Z.Ö.; Analysis and/or Interpretation - Y.G., S.B.A., H.K.Y.; Literature Search Y.G., Z.Ö.; Writing Manuscript - Y.G., Z.Ö.; Critical Reviews - S.B.A., H.K.Y.
Conflict of Interest: No conflict of interest was declared by the authors.

Financial Disclosure: The authors declared that this study has received no financial support.

\section{REFERENCES}

1. Hweidi IM. Jordanian patients' perception of stressors in critical care units: A questionnaire survey. Int J Nur Stud 2007; 44: 227235. [CrossRef]

2. Rattray J, Johnston M, Wildsmith JA. The intensive care experience: development of the ICE questionnaire. J Adv Nurs 2004; 47: 64-73. [CrossRef]

3. Rotondi AJ, Chelluri L, Sirio C, Mendelsohn A, Schulz R, Belle S, et al. Patients' recollections of stressful experiences while receiving prolonged mechanical ventilation in an intensive care unit. Crit Care Med 2002; 30: 746-752. [CrossRef]

4. Aronovich A, Ferraz MB, Knobel E. Stressors in ICU: Patient's evaluation. Intensive Care Medicine 1997, 23: 1282-1285. [CrossRef]

5. Bologh D, Kittinger E, Benzer a, Hackl JM. Noise in the ICU: Intensive Care Med 1993: 19: 343-346.

6. Zaal IJ, Spruyt CF, Peelen LM, Eijk MM, Scheineder MM, Kesecioğlu J, Slooter AJ: Intensıve care unit enviroment may affect the course of delirium. Intensive Care Med 2013, 39: 481-488. [CrossRef]

7. Parthasarathy S, Tobin MJ: Sleep in the intensive care unit. Intensive Care Med 2004, 30: 197-206. [CrossRef]

8. Ballard KS. Identification of environmental stressors for patients in a surgical intensive care unit. Issues Ment Health Nurs 1981, 1: 89-108. [CrossRef]

9. Nastasy EL. Identifying environmental stressors for cardiac surgery patients in a SICU. In: Proceedings of the 12th Annual National Teaching Institute of AACN. 1985, AACN. Newport Beach, CA, p357

10. Cornock M. Stress and the intensive care patient: perceptions of patients and nurses. J Adv Nurs 1998, 27: 518-527. [CrossRef]

11. Cochran J, Ganong L. A comparison of nurses and patients perceptionsof intensive cares unit stressors. J Adv Nurs 1989; 14: 1038-1043. [CrossRef]

12. Urden L, Stacy K, LoughM. Critical care nursing: diagnosis and management. $7^{\text {th }}$ ed. St. Louis: Mosby-Elsevier; 2014.

13. Soh K, Soh L, Ahmad Z, Raman R, Jabar S. Perception of intensivecare unit stressors by patients in Malaysian Federal Territory hospitals. Contemp Nurse 2008, 31: 86-93. [CrossRef]

14. Uçar H., Tunçay Y. Opinions of patients related to physical environment features of intensive care unit. Health Sciences Faculty Nursing Journal 2010; 33-46.

15. Zaal IJ, Spruyt CF, Peelen LM, Eijk MJ, Wientjes R, Schneider ME, et al. Intensive care unit environment may affect the course of delirium. Intensive Care Med 2013, 39: 481-488. [CrossRef]

16. So H, Chan D. Perception of stressors by patients and nurses of critical care units in Hong Kong. Int J Nurs Stud 2004, 41: 77-84. [CrossRef]

17. Puntillo K, Arai SR, Cooper BA, Stotts NA, Nelson JE. A randomized clinical trial of an intervention to relieve thirst and dry mouth in intensive care unit patients. Intensive Care Med. 2014, 40: 1295-1302.[CrossRef] 